\title{
PERCEPÇÃO DOS FRENTISTAS DE POSTOS DE COMBUSTÍVEIS DE MUNICÍPIOS DO RECÔNCAVO DA BAHIA SOBRE SUAS CONDIÇÕES DE TRABALHO
}

\section{PERCEPTION OF GAS STATION WORKERS IN MUNICIPALITIES OF THE RECÔNCAVO OF BAHIA OVER THEIR WORKING CONDITIONS}

\author{
Lusicleide Galindo da Silva Moraes \\ Jesus Manuel Delgado-Mendez ${ }^{2}$ \\ Luiz Gino Farina de Oliveira \\ Alexandre José Ribeiro Jacobina de Brito ${ }^{4}$ \\ José Carlos de Cerqueira Moraes ${ }^{5}$
}

\begin{abstract}
O objetivo deste estudo foi analisar as condições de trabalho e a percepção dos frentistas de postos revendedores de combustíveis do Recôncavo da Bahia quanto ao seu processo de trabalho. Trata-se de uma pesquisa exploratória e descritiva, de abordagem qualitativa que incluiu, além de entrevistas com os frentistas, a observação direta do local e da execução do trabalho. Os resultados mostram que os frentistas desenvolvem suas atividades expostos a riscos independente do gênero, idade e grau de escolaridade, e nem sempre recebem esclarecimentos suficientes que lhes permitam compreender e perceber a exposição constante aos diversos fatores de risco que permeiam os postos de combustíveis. Conclui-se que são grandes os desafios da Saúde do Trabalhador para garantir aos frentistas e a todos aqueles que trabalham em postos de gasolina, embora não operem as bombas, melhores condições de trabalho, com o mínimo ou nenhuma exposição.
\end{abstract}

Palavras-chave: Saúde do Trabalhador. Frentistas. Condições de Trabalho. Postos de Combustíveis.

The objective of this study was to analyze the working conditions and the perception of gas station attendants in the Recôncavo da Bahia. This was an exploratory and descriptive research within a qualitative approach. Data were collected by means of questionnaires applied to the attendants, and by direct observation of the facilities. It was found that the participants performed their activities exposed to risks regardless of gender, age and educational level. These workers did not receive information enough to be aware of their constant exposure to risk factors. Thus, the challenges of occupational health regulation authorities are significant in order to ensure better working conditions with minimum or no exposure of workers.

Keywords: Worker's Health. Gas Station Attendants. Working Conditions. Gas Stations.

\footnotetext{
${ }^{1}$ Docente da Faculdade Maria Milza - FAMAM, Mestre em Gestão de Políticas Públicas e Segurança Social pela Universidade Federal do Recôncavo da Bahia-UFRB. CV: http://lattes.cnpq.br/7865067981712306

2Doutor. Professor Titular da UFRB. CV: http://lattes.cnpq.br/5977100256638854; jesusd@uol.com.br

${ }^{3}$ Doutor. Professor Titular da Universidade de Bauru - SP. ${ }^{4}$ Gestor Ambiental. DIVAST-CESAT/SESAB. http://lattes.cnpq.br/7445867899455377; gino_professor@hotmail.com

${ }^{4}$ Gestor Ambiental. DIVAST-CESAT/SESAP. http://lattes.cnpq.br/9882007248590163

${ }^{5}$ Doutor. Professor Adjunto da Universidade do Estado da Bahia. CV: http://lattes.cnpq.br/5100206449999675
} 


\section{INTRODUÇÃO}

De acordo com a classificação brasileira de ocupações, o frentista é definido como atendente ou bombeiro de posto de gasolina (BRASIL, 2002). Esses trabalhadores, no entanto, desenvolvem as seguintes atividades: abastecimento de veículos, venda de produtos automotivos expostos nas estantes de amostras, recebimento de valores monetários, lavagem de para-brisas de veículos automotivos, verificação do nível da água e do óleo e calibragem de pneus.

Em alguns estabelecimentos os frentistas são ainda responsáveis pela higienização das ilhas e dos sanitários. O chefe de pista, função existente em apenas alguns postos, supervisiona o trabalho e, eventualmente, abastece veículos. No entanto, nos postos que não dispõem dessa função, a supervisão é realizada pelo gerente. Ambos podem ser responsáveis pela coleta de amostras de combustível retiradas diretamente do caminhão-tanque e utilizadas para análise da qualidade do produto que está sendo descarregado (BAHIA, 2014).

Para compreensão do processo de trabalho e identificação dos riscos ambientais, foi necessário descrever algumas dessas atividades já citadas. Inicialmente será descrito o abastecimento do veículo com etanol, gasolina ou diesel. Independentemente do tipo de combustível, o frentista ativa a bomba, abre a tampa do reservatório de combustíveis do carro e aciona o bico automático. No caso do gás natural veicular, abre- se o capô do veículo para fazer o aterramento e conectar o bico dispenser à válvula de abastecimento. Nessa última operação é obrigatório que o condutor e o(s) passageiro(s) do veículo se posicionem fora deste. Para verificação e complementação do nível do óleo, o capô é aberto, retira-se a vareta apropriada para esta finalidade e, quando necessário, se completa o óleo através do bocal de enchimento. Quanto ao nível da água do radiador e lavador de para-brisas, abre-se a tampa dos respectivos recipientes para enchê-los até o nível indicado. Além disso, esses trabalhadores realizam a lavagem dos para-brisas dos veículos, utilizando baldes com água e sabão e o "esfregão", fazendo movimentos para frente e para trás e para cima e para baixo (BAHIA, 2014).

A medição dos tanques também é uma atividade realizada diariamente nos postos revendedores de combustíveis que, geralmente, fica sob a responsabilidade do gerente ou chefe de pista, cabendo também ao frentista em alguns estabelecimentos. A mesma pode ser realizada manualmente, através da utilização de régua, ou eletronicamente, que consiste na forma mais correta de medição, por expor menos o trabalhador, uma vez que a aferição é realizada por intermédio de sondas interligadas a um computador e/ou registrador eletrônico (BAHIA, 2014).

Conhecer o processo de trabalho constitui um aspecto fundamental para se compreender que esses trabalhadores desenvolvem as suas atividades expostos a diversos riscos ocupacionais, uma vez que executam atividades de potencial dano à sua saúde e ao meio ambiente, estabelecido, principalmente, em razão da natureza e da intensidade do agente e do tempo de exposição aos seus efeitos. Vale ressaltar que não existe limite seguro para a exposição ao benzeno, uma vez que é uma substância carcinogênica que pode funcionar como depressora do sistema nervoso central ou causadora de hemopatias.

\section{MÉTODOS}

Com base nos seus objetivos, a pesquisa foi classificada como exploratória e descritiva, pois mostra as características de um grupo de trabalhadores, os frentistas. Quanto à abordagem, foi qualitativa, incluindo diversas formas de interpretação dos dados coletados, visando possibilitar a compreensão do problema que, neste caso, está representado pelas condições de trabalho dos frentistas.

Aárea de estudo é o Território do Recôncavo da Bahia e, para realização da coleta de dados, foram escolhidos 10 dentre os 20 municípios do Recôncavo. Foram eles: Santo Antônio de Jesus, Cruz das Almas, São Francisco do Conde, Muritiba, São Sebastião do Passé, Santo Amaro da Purificação, 
Governador Mangabeira, Maragogipe, Castro Alves e Varzedo. Através de uma amostra aleatória simples foram sorteados os postos de combustíveis e os frentistas foram selecionados.

As informações foram distribuídas de acordo com a classe de municípios, sendo elas A, B, C e D. Os sujeitos do estudo foram representados por uma amostra de 62 dos 243 frentistas que estavam trabalhando nos municípios e postos escolhidos, no período de março a abril de 2016 . Os critérios utilizados para garantir a aleatoriedade do processo de seleção foram: frentistas que atuam nessa atividade; que estavam presentes no período da coleta de dados nos turnos matutino ou vespertino e que consentiram livremente participar na pesquisa. Por contraste, foram critérios de exclusão: frentistas que estavam de folga, afastados por motivo de férias ou licença de qualquer natureza e aqueles que não concordaram em assinar o Termo de Consentimento Livre Esclarecido.

Foi aplicado um roteiro de entrevista semi-estruturada, com informações sobre os dados gerais de identificação, condições de trabalho e alguns aspectos relacionados à saúde.

O projeto de pesquisa foi enviado, por meio de um protocolo, ao Comitê de Ética e Pesquisa da Universidade Federal do Recôncavo da Bahia (CEP-UFRB), para apreciação e aprovação. Após a obtenção do parecer (número 1.430.74) favorável , a pesquisa foi executada.

\section{RESULTADOS EDISCUSSÃO}

Foram entrevistados 62 frentistas de um total de 243 que trabalham nos 30 postos amostrados em 10 dos 20 municípios do Recôncavo, adotando-se a aplicação de questionário orientado para a coleta de informações sobre os dados de identificação, condições de trabalho e alguns aspectos relacionados à saúde, como os expostos a seguir.

Com relação ao gênero dos entrevistados, identificou-se a porcentagem de homens e mulheres que participaram do estudo. Verificou-se que $24,2 \%$ dos entrevistados eram do sexo feminino e $75,8 \%$ do sexo masculino.

Observando a trajetória da saúde do trabalhador, parece indicativo que existem programas e políticas que esboçam essa preocupação, mas que ainda precisam de maior efetividade nas suas ações. Em 2012 foi elaborada a Política Nacional de Saúde do Trabalhador e Trabalhadora, que possui como estratégias principais a integração da VISAT com todos os níveis de atenção à saúde e análise do perfil produtivo e da situação de saúde desses trabalhadores (BRASIL, 2012).

Quanto ao nível de escolaridade, nota-se que a maior parte dos entrevistados enquadrou-se no ensino fundamental incompleto e médio completo, representados por $12,92 \%$ e $69,35 \%$, respectivamente, quando comparado entre municípios. O Departamento Intersindical de Estatística e Estudos Socioeconômicos (DIEESE) corrobora os dados obtidos nesta pesquisa ao afirmar que é comum encontrar, em todo o Recôncavo da Bahia e demais regiões, maior número de trabalhadores que possuem nível médio completo exercendo a função de frentistas (DIEESE, 2014).

Com relação ao tempo de atuação, em anos, os frentistas foram distribuídos considerando-se intervalos de até 1 ano na função, de 1 a 5 anos, de 6 a 10 anos, de 11 a 15 anos, de 16 a 20 anos e mais de 21 anos de atuação na área. Sendo assim, observou-se que $50 \%$ dos entrevistados exercem a função de frentista de 1 a 5 anos; outros 16,13\% atuam há menos de um ano na sua atividade. Nos grupos de 6 a 10 e de 11 a 15 anos no trabalho, encontram-se $12,9 \%$ dos entrevistados, em cada um, enquanto que $3,22 \%$ e 4,83\% estão entre 16 a 20 anos e mais de 21 anos, respectivamente.

Considerando que aproximadamente $2 / 3$ dos entrevistados desempenham seus labores de frentista entre 1 e 15 anos e entendendo que não há limite seguro para exposição ao benzeno do combustível, chama a atenção que o tempo de atuação é importante para ressaltar que é de fundamental importância o investimento em adoção de medidas que objetivem preservar a saúde desses trabalhadores, que desenvolvem as suas atividades expostos a riscos em período de tempo prolongado, considerando os anos de atuação, e que podem desenvolver doenças relacionadas ao trabalho 
decorrentes da exposição aos riscos ambientais e especialmente ao benzeno. A gasolina apresenta diversas substâncias nocivas à saúde, a exemplo do benzeno, em cujo caso o tempo prolongado de exposição é um fator de risco. No entanto, mesmo com pouco tempo de serviço e exposição a baixas concentrações, é possível o adoecimento.

Conforme Barata-Silva e colaboradores (2014), a exposição crônica e de baixa concentração ao benzeno pode favorecer o surgimento de patologias como, por exemplo, alterações sanguíneas (anemia aplástica e leucemia), linfoma não-Hodgkin, mieloma múltiplo, alterações cromossômicas que causam má formação fetal e infertilidade masculina. Na exposição aguda pode ocorrer cefaleia, fadiga, tontura, convulsão, depressão e, até mesmo, falência respiratória, o que possivelmente levará a óbito.

Quando questionados sobre o vínculo empregatício, verificou-se que 93,55\% dos entrevistados possuem carteira assinada, o que caracteriza o vínculo. Apenas 6,45\% não possuem. Observou-se, portanto, na análise desses dados que a precariedade do trabalho relacionada ao vínculo empregatício e às garantias de direitos trabalhistas ainda existem. As leis trabalhistas não são seguidas ou respeitadas conforme deveriam, uma vez que os direitos do trabalhador devem ser garantidos desde o primeiro dia de trabalho.

Conforme exposto no art. $3^{\circ}$ da Portaria $n^{\circ} 1.823$, de 23 de agosto de 2012 que institui a Política Nacional de Saúde do Trabalhador e da Trabalhadora, todos os trabalhadores, independente da forma de inserção no mercado de trabalho (formal ou informal) e do vínculo empregatício (público ou privado), têm garantido o direito à saúde baseado nos princípios e diretrizes do SUS (BRASIL, 2012).

Com relação às informações relativas à jornada de trabalho dos frentistas, observou-se que a maior proporção dos entrevistados trabalha de 6 a 12 horas por dia. Destaca-se que houve manifestação da existência de carga horária diária que ultrapassa às 8 horas, chegando até 24 horas de trabalho, mostrando que os frentistas trabalham horas extras e em escala de plantão.

Conforme a Convenção Coletiva de Trabalho 2016/2017 do Sindicato dos Trabalhadores de Postos de Combustíveis e Derivados do Petróleo da Bahia, a carga horária diária não deve ultrapassar 8 horas e 44h/semana, de acordo com a Consolidação das Leis Trabalhistas - CLT. No entanto, as empresas representantes dos postos podem realizar acordos de horário diferenciado, junto ao sindicato da categoria profissional (BAHIA, 2016).

Em observação de campo e entrevistas informais com representante do sindicato foi possível depreender que os acordos entre os postos e seus representantes não se realizam como proposto pela legislação.

Com relação à distribuição dos frentistas entrevistados em função dos períodos das jornadas de trabalho, constatou-se que há maior concentração de trabalhadores no turno da manhã, representado por $41,94 \%$ dos entrevistados, seguido pelos $30,65 \%$ que trabalham de manhã e tarde e os $11,29 \%$ que trabalham nos três turnos. Os que trabalham somente no turno da tarde são 9,68\%. No turno da tarde e noite estão $4,84 \%$ e no turno da noite apenas $1,61 \%$, não havendo, portanto, trabalhadores nos turnos manhã e noite.

Observando a organização da jornada de trabalho dos frentistas, percebeu-se que a maior proporção de trabalhadores no turno da manhã pode estar relacionada com a maior movimentação e rotatividade de veículos para abastecimento. Ressalta-se, portanto, que há um número representativo de trabalhadores que exercem as suas atividades em três turnos (manhã, tarde e noite), caracterizando jornada prolongada de trabalho e que, mesmo compensado com folgas, descumprem as leis trabalhistas, mas decorrem dos acordos internos entre proprietários e empregados.

Para complementar as informações apresentadas nesta seção, os frentistas foram identificados segundo gênero, estado civil e turno de trabalho. Assim, verificou-se que essa atividade ainda possui maior representatividade de homens, quando comparado com o número de mulheres, alcançando $24,19 \%$ de frentistas do sexo feminino. Dentre todas as mulheres entrevistadas, $46,67 \%$ são solteiras (equivalente a $11,29 \%$ desse $24,19 \%$ ). Já entre os homens, observou-se certo equilíbrio entre os solteiros e os casados, cuja proporção ficou em 40,35 e 42,48\%, respectivamente. No entanto, se consideramos que a união estável pode ser somada à proporção de casados, a porcentagem destes aumentaria até $15 \%$, aproximadamente.

Também observou-se que a maior parte das mulheres, independente do estado civil, trabalha em 
horários semelhantes aos homens, havendo uma preferência pelos turnos da manhã e da manhã e tarde, para ambos os sexos.

Os dados da Relação Anual de Informações Sociais - RAIS, referentes ao ano de 2013, apresentados em pesquisa realizada pelo DIEESE, mostra que o perfil de trabalhadores de postos revendedores de combustíveis de municípios do Recôncavo da Bahia continua apresentando o predomínio de trabalhadores do sexo masculino (DIEESE, 2014).

Quanto às atividades realizadas pelos frentistas segundo seu gênero, a Tabela 1 mostra que todos os homens e mulheres entrevistados realizam limpeza de para-brisas, abastecimento e conferem água e nível de óleo. Com relação ao recebimento de valores monetários, verificou-se que 59,68\% dos homens e $17,74 \%$ das mulheres são responsáveis pelo caixa. Outros $59,68 \%$ dos homens e $19,36 \%$ das mulheres são responsáveis pela limpeza da área dos postos.

Com relação às medidas manuais dos tanques de combustíveis, $54,36 \%$ dos homens e $8,07 \%$ das mulheres são responsáveis por realizá-las. A venda de lubrificantes é realizada por $16,13 \%$ dos homens e $4,84 \%$ das mulheres. E em se tratando da calibragem de pneus, a mesma é realizada tanto pelos homens quanto pelas mulheres, sendo representado por 48,40\% e 12,90\%, respectivamente.

Verificou-se que não existe distinção da realização de atividades devido ao sexo, pois ambos realizam as mesmas atividades. De acordo com a Classificação Brasileira de Ocupações (CBO) do Ministério do Trabalho e Emprego (MTE), o trabalho do frentista consiste no abastecimento; troca ou complemento de óleo e água; limpeza de para-brisas e janelas; enchimento e calibragem de pneus através do uso de bombas, equipamentos e materiais próprios, visando favorecer o bom desempenho dos veículos. Além disso, os trabalhadores realizam também o serviço de caixa, que consiste na verificação do painel de bomba e na realização das operações financeiras (BRASIL, 2002).

Analisando os resultados apresentados, percebe-se que as atividades designadas ao frentista dos postos revendedores de combustíveis de municípios da Bahia, em alguns casos, extrapolam o que é preconizado pelo CBO do MTE, especialmente no que se refere às atividades de venda, limpeza da área do posto, análise de combustíveis e demais atividades distanciadas das estabelecidas na legislação.

No desempenho dos labores, os frentistas expõem-se a riscos existentes no ambiente de trabalho. Esses riscos foram classificados como químicos, físicos, biológicos, ergonômicos e de acidentes, apresentados nas figuras a seguir.

O primeiro deles, o risco químico, foi exposto na Figura 1, onde se mostrou a exposição dos frentistas a poeiras, gases, vapores e substâncias ou compostos químicos. Note-se, que guardadas as devidas proporções entre os municípios, todos os riscos parecem proporcionais em cada um deles.

Figura 1. Exposição dos frentistas a riscos químicos no ambiente laboral, em 10 municípios do Recôncavo da Bahia.

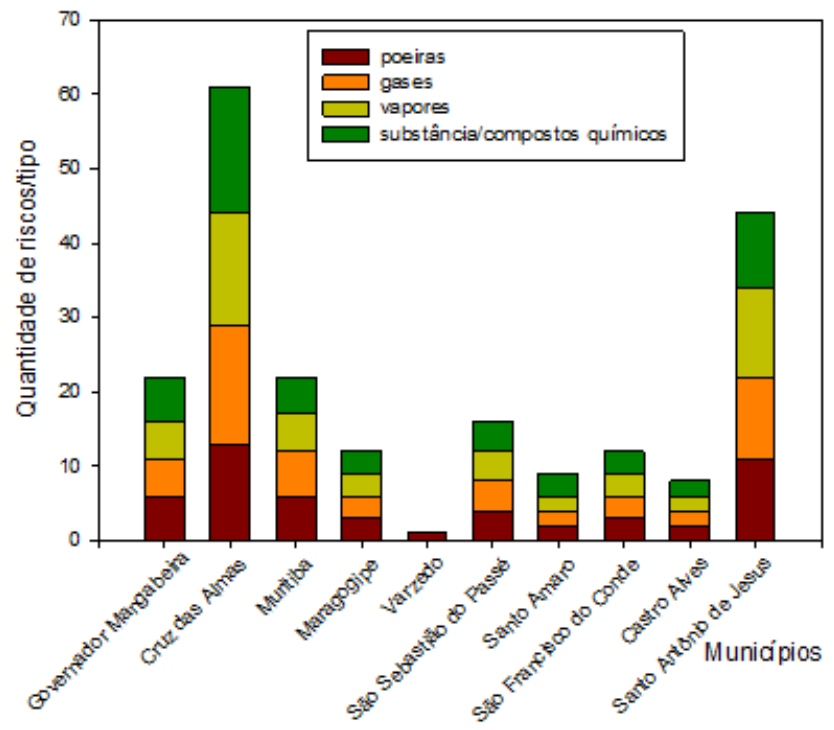


Analisando os dados apresentados na Figura 1, observou-se que a exposição do trabalhador aos riscos químicos estava presente em quase todos os municípios amostrados, com exceção do município de Varzedo, onde foi relatada a exposição apenas à poeira.

Existe uma grande preocupação dos estudiosos em relação ao potencial carcinogênico dos compostos químicos, especialmente quando a simples presença do mesmo no meio ambiente caracteriza risco potencial (BRILHANTE, 1999).

Em seguida, a Figura 02 traz informações sobre os riscos físicos, e assim, verificou-se que a exposição à vibração, ruídos, frio e calor foram relatadas na maior parte dos municípios amostrados, com exceção apenas de Varzedo.

Figura 2. Exposição dos frentistas a riscos físicos no ambiente laboral, em 10 municípios do Recôncavo da Bahia.

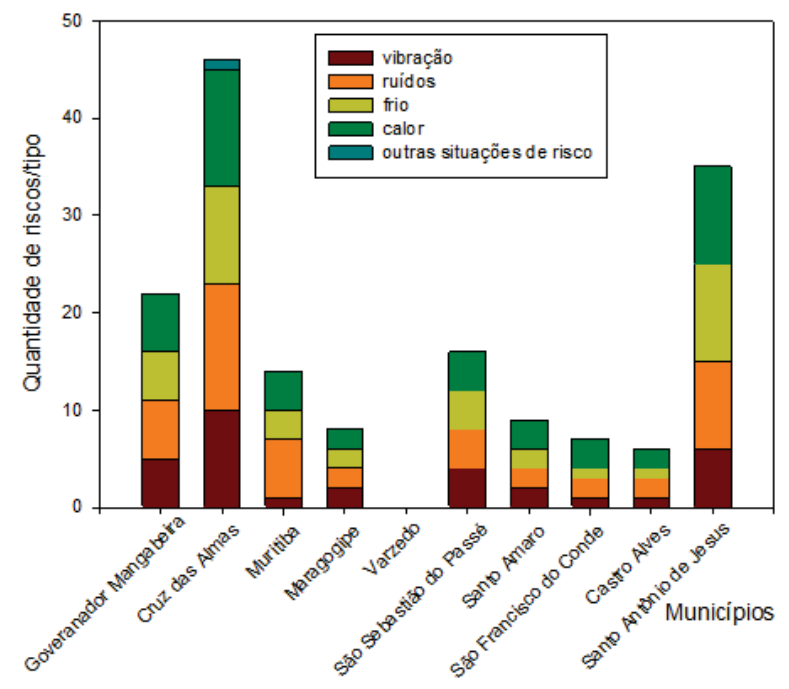

A Figura 3 mostra que em $80 \%$ dos postos nos municípios visitados, um dos riscos biológicos mais comuns foi água empoçada. Quanto ao acúmulo de resíduos sólidos/lixo visível nas proximidades da ilha de abastecimento, ele só foi visto e relatado em apenas um posto do município de Castro Alves.

Figura 3. Exposição dos frentistas a riscos biológicos no ambiente laboral, em 10 municípios do Recôncavo da Bahia

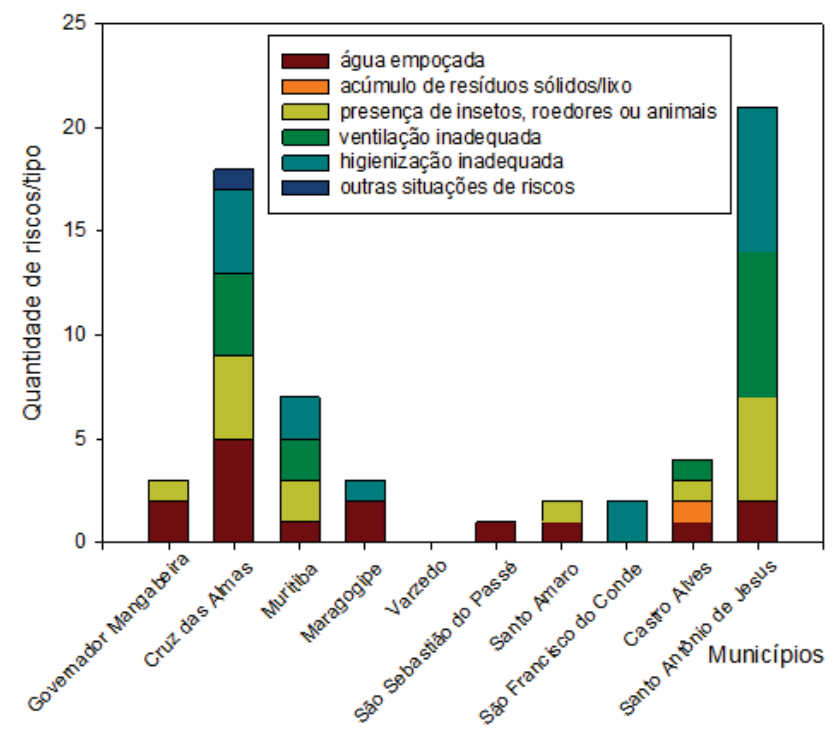


Nos postos de seis municípios foi relatada a presença de insetos, roedores ou animais. A ventilação inadequada, devido à localização do estabelecimento, também foi indicado em 4 dos 10 municípios. As condições de higiene também foram analisadas e foram consideradas inadequadas em postos de 5 municípios.

Nos postos visitados, foram encontrados também riscos ergonômicos, tais como esforço físico intenso, levantamento e transporte manual de peso, exigência de postura inadequada, ou seja, permanência prolongada na postura bípede, controle rígido da produtividade (ou funções que produzem tensão muscular corporal), jornada de trabalho prolongada, monotonia e repetitividade. Além dos já citados, alguns entrevistados destacaram outras situações, como por exemplo, a falta de assento adequado para descanso, dentre outras.

A Figura 4 fornece informações sobre a exposição aos riscos de acidentes nos postos de combustíveis dos 10 municípios do Recôncavo sob estudo. Analisando os riscos citados, observou-se que na maior parte dos municípios há preocupação com o risco de acidentar-se com máquinas e equipamentos sem proteção. Em apenas três municípios foi citada a presença de ferramentas inadequadas ou defeituosas que também podem ser responsáveis pelos acidentes no ambiente laboral. Quanto à probabilidade de incêndio ou explosão, foi citada em quase todos os municípios. Em se tratando, portanto, do item outras situações de risco que poderão contribuir para a ocorrência de acidentes, tais como atropelamentos, etc. foram citados em todos os municípios.

Figura 4. Exposição dos frentistas a riscos de acidentes no ambiente laboral, em 10 municípios do Recôncavo da Bahia.

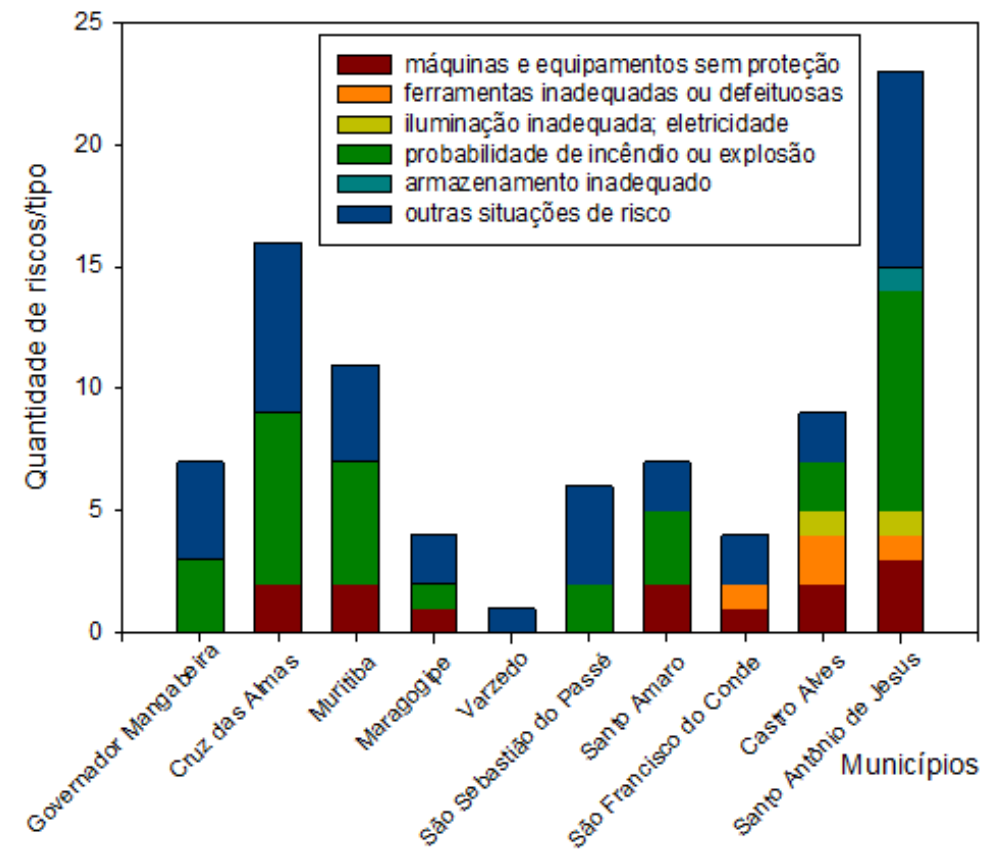

$\mathrm{Na}$ avaliação da exposição do trabalhador aos riscos ambientais, merecem destaque os agentes químicos que são vistos com grande preocupação pela Saúde Ambiental, destacando-se a prevenção dos danos à saúde causados por substâncias químicas presentes no meio ambiente, ao passo que torna indispensável a identificação e quantificação deste risco considerado inaceitável à exposição humana (AMORIM, 2003).

De forma geral, os resultados relacionados aos riscos ambientais estão presentes em quase $100 \%$ dos postos dos municípios amostrados. Dessa maneira, é válido destacar a importância do trabalhador inserido nesse contexto, conhecer os riscos inerentes à sua profissão e como poderá minimizar a sua exposição a esses fatores que podem causar danos a sua saúde e ao meio ambiente. 
Durante a entrevista, os frentistas foram questionados quanto à participação em cursos de atualização e à existência de alguns programas, comissões e normas, além de preparação no combate a incêndios. Quanto à realização dos cursos de atualização, somente nas classes Ae B, 83,3\% e 50,0\%, afirmaram que participam desses cursos, respectivamente.

Quando questionados sobre a existência do Programa de Prevenção de Risco Ambiental (PPRA); Comissão Interna de Prevenção de Acidentes (CIPA); Mapa de Risco (MR); Licenciamento Ambiental; Atestado de Saúde Ocupacional (ASO) e curso de combate à incêndio, verificou-se que o PPRA foi citado nas classes A, B e C, por 50,0\%, 20,0\% e 40,0\%, respectivamente. ACIPA foi citada por $36,1 \%$ na classe $A$ e $45,0 \%$ na B. O MR, por sua vez, mostrou-se nas classes A, B e C, com $52,8 \%, 45,0 \%$ e $20,0 \%$, respectivamente. Quanto ao licenciamento ambiental, o mesmo foi referido em todas as classes pela maior parte dos entrevistados. Já o ASO, citado pela maioria na classe A, foi representado por $69,4 \%$, mostrando-se menos frequente nas classes B e C, com percentuais de 40,0\% e 20,0\%, respectivamente. Por fim, quando questionados sobre a realização do curso de combate a incêndios, a resposta foi afirmativa para a maioria dos entrevistados nas classes $A, B$ e $D$, ficando a $C$ com a menor representatividade $(40,0 \%)$.

Após esses questionamentos, foi perguntado aos frentistas se os mesmos possuem conhecimento sobre os itens já mencionados. Aeste respeito, a maioria afirmou conhecer.

Os cursos de atualização devem ser oferecidos e constituem um direito do trabalhador, pois possibilitam adquirir conhecimento sobre as atividades que desenvolve, seus riscos e a importância da adoção e uso adequado das medidas de proteção.

Alguns aspectos merecem destaque no âmbito dos postos revendedores de combustíveis. Devido ao potencial poluidor e aos riscos existentes nas atividades desenvolvidas nesses estabelecimentos, os itens como PPRA, mapa de risco e licenciamento ambiental, se fazem indispensáveis.

A CIPA não é obrigatória nos postos de combustíveis, mas conforme elaborado na NR5, é imprescindível que seja designado um trabalhador/ frentista (BRASIL, 2011). No entanto, observou-se que a maior parte dos postos visitados não possui esse trabalhador designado.

Sobre os aspectos relacionados à saúde dos frentistas, foram questionados sobre a realização de exame admissional, exames periódicos e de imunização. Na análise verificou-se que 74,20\% e 62,90\% dos frentistas entrevistados afirmam ter realizado os exames admissional e periódicos, respectivamente. Quanto à imunização, aproximadamente dois terços possuem cartão de vacinação atualizado.

Conforme estabelecido pela norma regulamentadora NR07, relacionada ao Programa de Controle Médico de Saúde Ocupacional - PCMSO, os exames admissionais e periódicos (sangue e urina) devem ser garantidos ao trabalhador, com o objetivo de detectar precocemente as doenças relacionadas ao trabalho (BRASIL, 2013). Além disso, é importante que esses indivíduos possuam cartão de vacinação atualizado, pois algumas doenças que podem ser adquiras no ambiente laboral são imunopreveníveis, como por exemplo tétano, febre amarela, hepatite B, etc.

Os entrevistados foram ainda questionados quanto à ocorrência de faltas ao trabalho e verificou-se que $67,76 \%$ já faltaram ao trabalho por motivos diferenciados, sendo que apenas $6,45 \%$ afirmaram que já tiveram problemas de saúde relacionados com sua função. Dentre os problemas citados estão a perda auditiva induzida pelo ruído, varizes, dor no peito e "queimação" no estômago. Quanto aos acidentes de trabalho, apenas $11,3 \%$ afirmam ter se acidentado. Os acidentes citados foram atropelamento, queda da própria altura e acidente de percurso ao trabalho.

Conforme os dados coletados, identificou-se que os EPI disponíveis são óculos (16,13\%); botas (79,03\%); farda (74,20\%); protetor auricular (4,83\%); máscara facial $(67,74 \%)$ e luvas $(27,42 \%)$. Vale ressaltar, portanto que esses equipamentos são disponibilizados, mas não são usados de forma adequada.

Desse modo, os EPI devem ser recomendados quando não for viável a implantação das medidas de proteção coletivas, ou quando estas não protegerem os trabalhadores. O uso desses equipamentos nos postos deve considerar as situações reais de trabalho, as características dos equipamentos e as particularidades de cada trabalhador, além de ser de suma importância garantir efetivamente a avaliação 
do seu uso cotidiano (BAHIA, 2014).

Verificou-se ainda, para complementar as informações acerca dos EPI disponíveis, que $77,4 \%$ dos entrevistados afirmaram que usam os equipamentos, e $87,1 \%$ sabem para que servem. Em alguns postos visitados, os equipamentos foram vistos guardados em gavetas ou usados de forma incorreta. A adoção dessas medidas de maneira efetiva depende, portanto, do compromisso entre o proprietário dos postos e os trabalhadores. Isso depende também de um processo educativo que permita favorecer e incentivar melhorias no ambiente laboral.

Em relação aos equipamentos de proteção coletiva disponíveis nos postos sob estudo, percebeuse que a maior proporção dos frentistas, representados por $32,26 \%$, citou o extintor como equipamento que visa a proteção coletiva. Outros itens foram também citados, tais como para-raios $(4,84 \%)$, cones (6,45\%), lâmpada de emergência (1,61\%), sinalização de segurança $(1,61 \%)$ e chave de luz $(1,61 \%)$.

Os entrevistados foram questionados se o posto possui ou não EPC. Dentre eles, $56,45 \%$ responderam que sim. Em seguida, perguntou-se se eles conheciam esses equipamentos e sua utilidade, e a resposta foi positiva para $58,06 \%$ dos entrevistados. Confrontando os dados de ambas as questões, percebe-se que há certa inconsistência nas respostas, pois mais da metade afirmou ter os equipamentos nos lugares de trabalho; porém, poucos deles (os EPC) foram citados e, os considerados mais importantes, nem sequer foram mencionados.

A legislação tem avançado em relação à adoção de medidas de proteção coletiva, relacionadas à exposição do benzeno em postos revendedores de combustíveis no Brasil, mesmo diante da resistência entre os representantes dos postos. Recentemente, houve elaboração de um anexo relacionado à norma regulamentadora, a NR 09 do Programa de Prevenção de Riscos Ambientais, que estabelece prazos para adequação dos postos no sentido de adquirir bombas de abastecimento com instalação do sistema de captação de vapores (BAHIA, 2016).

Os prazos sugeridos são relativamente longos, variando de 72 a 180 meses, considerando todos os danos que são causados à saúde do trabalhador e ao meio ambiente. Vale ressaltar, ainda, que as medidas poderiam e deveriam também incluir a exigência da instalação do sistema de captação de vapores no descarregamento do caminhão nos tanques subterrâneos de combustíveis.

Quanto à concepção dos frentistas em relação à exposição ao benzeno existente no combustível e a sua relação com as alterações dos elementos do sangue, bem como o surgimento da leucemia, os resultados encontrados demonstraram que $83,88 \%$ dos entrevistados afirmaram que essa exposição pode ser responsável pelas alterações nas células sanguíneas e, consequentemente, pelo surgimento da leucemia.

O benzeno é um hidrocarboneto aromático que, juntamente com o tolueno, etilbenzeno e os isômeros de xileno (BTEX), são constituintes da gasolina e mostram-se como potenciais depressores do sistema nervoso central. Vale ressaltar, ainda, que o benzeno é também considerado potencialmente carcinogênico (IARC, 1998).

Para combustíveis derivados do petróleo, é permitido encontrar um valor percentual menor ou igual a 1\% (ACURI; CARDOSO, 2005). Já a Agência Nacional de Petróleo - ANP considera tolerável o percentual de até $1,3 \%$ de benzeno, sendo que a adulteração dos combustíveis contribui para elevação desse percentual, podendo chegar a $8 \%$.

Estudos realizados mostram que não existe limite seguro de exposição a essa substância que, mesmo em pequenas concentrações, promove alterações na contagem de leucócitos, podendo levar à leucemia e problemas neurológicos.

\section{CONSIDERAÇÕES FINAIS}

De acordo com os dados analisados, percebe-se que independentemente do gênero, idade e grau de escolaridade, os frentistas atuam em postos de combustíveis expostos aos riscos inerentes às 
suas atividades e ao local. Dentre os riscos ambientais existentes destaca-se a exposição ao benzeno, substância carcinogênica, que compromete a saúde dos expostos, que nem sempre tem noção da potencialidade dessa substância e dos riscos à sua saúde. Isso reforça a necessidade urgente da adoção de medidas de proteção coletiva e do fortalecimento das Políticas Públicas Ambientais e de Saúde do Trabalhador que visam a promoção da saúde e segurança no trabalho.

\section{REFERÊNCIAS}

ACURI, A. S. A.; CARDOSO, L. M. N. Acordo e legislação sobre o benzeno 10 anos. São Paulo: Fundacentro, 2005. $135 \mathrm{p}$.

AMORIM, Leiliane Coelho André. O uso dos biomarcadores na avaliação da exposição ocupacional a substâncias químicas. Rev. Bras. Med. Trab., Belo Horizonte, v. 1, n. 2, p. 124-132, out./dez. 2003.

BAHIA. Secretaria da Saúde do Estado da Bahia. Superintendência de Vigilância e Proteção à Saúde. Diretoria de Vigilância e Atenção à Saúde do Trabalhador. Centro Estadual de Referência em Saúde do Trabalhador. Orientações técnicas para ações de vigilância de ambientes e processos de trabalho em postos de revenda de combustíveis - SUS/BAHIA. SESAB/SUVISA/DIVAST. Salvador: CESAT/DIVAST, 2014.

BAHIA, 2016. Convenção coletiva de trabalho. Sinposba. 2016/2017.

BRASIL. Saúde do trabalhador. Cadernos da Atenção Básica. Programa de Saúde da Família, n 5. Brasília: Ministério da Saúde, 2002.

NR 5 - Comissão interna de prevenção de acidentes. Portaria GM n. ${ }^{\circ} 3.214$, de 08 de junho de 1978. Alteração/Atualização. Portaria SIT n. ${ }^{\circ}$ 247, de 12 de julho de 2011. Disponível em: Acesso em: 03 de junho de 2016.

Portaria 1.823, de 23 de Agosto de 2012. Política Nacional de Saúde do Trabalhador e da Trabalhadora. Disponível em: < http://bvsms.saude.gov.br/bvs/saudelegis/gm/2012/prt1823_23_08_2012.html> Acesso em: 20 de ago. de 2016.

NR 7 - Programa de Controle Médico de Saúde Ocupacional. Portaria GM n. ${ }^{\circ} 3.214$, de 08 de junho de 1978. Alteração/Atualização Portaria MTE n. ${ }^{\circ}$ 1.892, de 09 de dezembro de 2013. Disponível em: Acesso em: 04 de junho de 2016.

BARATA-SILVA, C.; MITRI, S.; PAVESI, T.; SAGGIORO, E.; MOREIRA, J. C. Benzeno: reflexos sobre a saúde pública, presença ambiental e indicadores biológicos utilizados para a determinação da exposição. Cad. Saúde Colet., 2014, Rio de Janeiro, 22 (4): 329-42. Disponível em: Acesso em: 20 de nov. de 2016.

BRILHANTE, O.M.; CALDAS, L.Q.A., coord. Gestão e avaliação de risco em saúde ambiental [online]. Rio de Janeiro: Editora FIOCRUZ, 1999. 155 p. ISBN 85- 85676-56-6 Available from SciELO Books .

DIEESE. Perfil dos Trabalhadores no Segmento do Comércio Varejista de Combustíveis para Veículos Automotores. Sindicato dos Trabalhadores em Postos de Combustíveis da Bahia - SINDPOSBA. Ano: 2013, Set, 2014.

INTERNATIONAL AGENCY FOR RESEARCH ON CANCER - IARC. Monographs on the Evaluation of Carcinogenic Risck to Humans. France, 1998. Vol. 45. 